\title{
POSITIONING OF CUBES ON A BREAKWATER SLOPE
}

\author{
Henk Jan Verhagen ${ }^{1}$, Kees d'Angremond ${ }^{2}$, and Kees van der Vliet ${ }^{3}$
}

\begin{abstract}
Recent research has shown that it is possible to use concrete cubes as a single armour layer on breakwaters. However, this is only possible in case a placing density of at least $70 \%$ is achieved. In lab-tests it is no problem to place cubes with this density, however it is questionable if such a placing density can be achieved in prototype situations. A number of tests have been carried out in order to determine the requirements for dropping concrete blocks from a crane onto a breakwater slope. The conclusion is that at a waterdepth of approximately 10 times the block size this just can be achieved and that at smaller depth this placing density can be reached without too many difficulties. However, in all cases a good quality toe is vital for a high placing density. Blocks have to be placed at an angle of $45^{\circ}$ with respect to the breakwater axis; blocks placed parallel to the breakwater axis will lead to large voids.
\end{abstract}

\section{INTRODUCTION}

Armour of breakwaters can be either natural rock or concrete units. Although usually natural rock is to be preferred (usually it is cheaper), sometimes it is not possible to apply it. Often simply because the required weight of the individual blocks is not available. In that case, concrete elements have to be used. Cubes are simple, cheap in production, but require quite some concrete. The advantage of Tetrapod and Dolos is that they require less concrete, but their formwork, as well as their placing is more complicated, and consequently more costly. This is even more true for the Accropod, but this element has the clear advantage that it can be placed in only one layer. And this gives a considerable cost saving.

It is therefore interesting to investigate if it is possible to use one-layer systems also with cubes or Tetrapods. Basically, this should be possible if the layer our armour units can

\footnotetext{
1 Associate Professor, Delft University of Technology, Section of Hydraulic Engineering, P.O. Box 5048, NL2600GA Delft, The Netherlands, H.J.Verhagen@ct.tudelft.nl.

2 Emeritus Professor, Delft University of Technology, section of Hydraulic Engineering, P.O. Box 5048, NL2600GA Delft, The Netherlands.

3 M.Sc. Student, Delft University of Technology.
} 
guarantee that the filter layer is not washed out. This implies relatively small voids between the elements.

VAN GENT \& SPAAN [1998] have proved that for cubes a one-layer system is possible, provided that the placing density or packing density is larger than $70 \%$. As reported by VAN DEN BOSCH ET AL. [2002] at this conference, also a one-layer system with tetrapods is feasible.

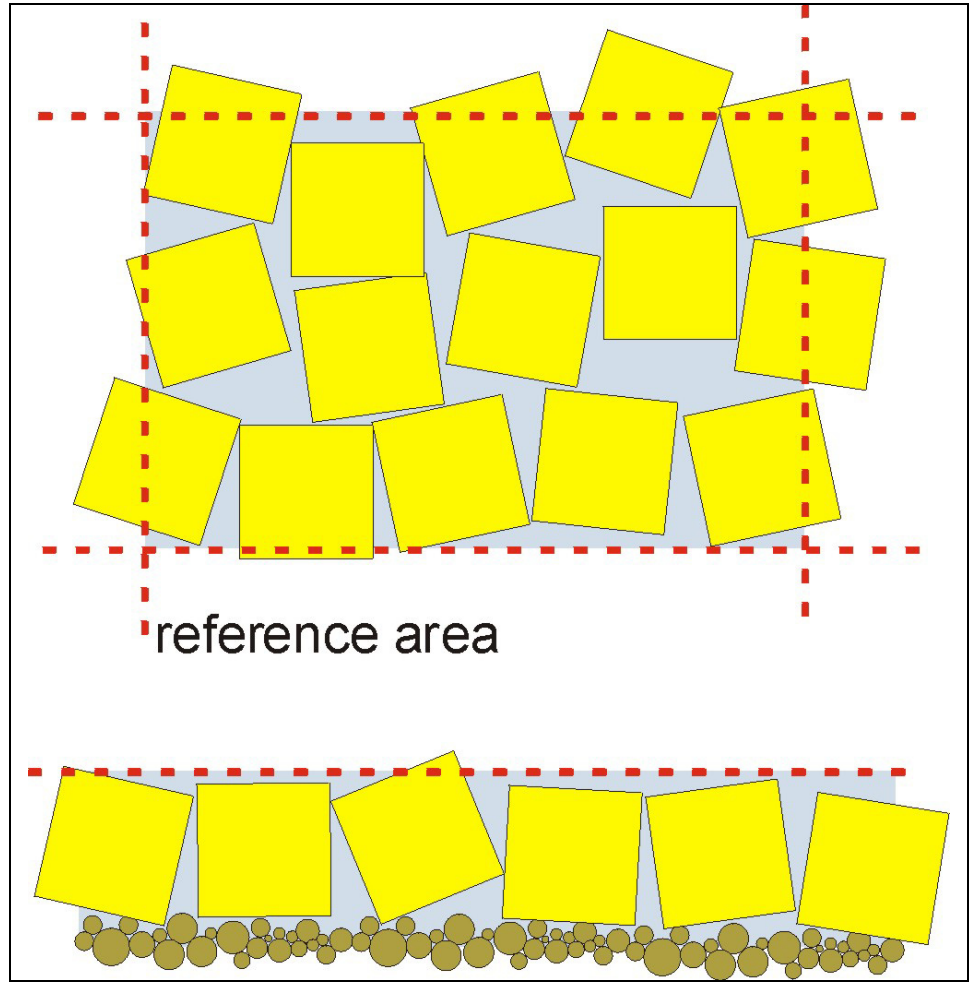

Fig. 1. Placing density (top) and porosity

\section{PACKING DENSITY AND POROSITY}

The basis of the definition of placing density or packing density is the number of elements $(\mathrm{N})$ per $\mathrm{m}^{2}$. The placing density is then given by dividing the size of he blocks by the thickness of the "equivalent layer thickness". With other words, the placing density is the percentage of the area of the surface covered by blocks, in case all blocks are placed flat on the surface. In reality, the blocks are not placed flat on the surface. There is also a hollow space between the blocks and the underlayer. In addition, the defined top of the blocks is not exactly the upper side of the block. Here also is a space.

If one calculates the volume of the layer and divides that by the volume of the concrete of the block, one gets the porosity of the layer.

$$
\begin{aligned}
& d_{l}=\left(1-n_{p}\right) D_{\text {cube }} \\
& N=\frac{d_{l}}{D_{\text {cube }}^{3}}
\end{aligned}
$$

In which:

$d_{l} \quad$ equivalent layer thickness

$n_{p} \quad$ placing density 
$D_{\text {cube }} \quad$ size of the cube

$N \quad$ Number of cubes per $\mathrm{m}^{2}$

For nicely placed blocks, the placing density is equal to (1- porosity.)

$$
n_{v}=1-\frac{D_{c u b e}^{3} N}{d}
$$

in which:

$n_{v} \quad$ porosity

$d \quad$ measured layer thickness

In figure 1 both porosity and placing density are illustrated. The placing density is given in the upper figure, and can be calculated by dividing the area of the blocks by the area of the control area. In the lower figure is indicated that also below and above the blocks there is an "empty" space. The volume not used by concrete divided by the total volume is the porosity. If one compares the measured porosity and the placing density with the values assuming a "flat" positioning of the cubes, a difference becomes apparent. This indicates that there is a small difference.

As illustrated by equation 2, for the computation a "measured layer thickness" is needed. In reality often one cannot measure this value and it is assumed that

$$
d=K_{d} \cdot D_{\text {cube }}
$$

in which $K_{d}$ is the layer factor, usually assumed 1.1. Figure 2 illustrates that in the tests the $K_{d}$ value is somewhat more than 1.1.

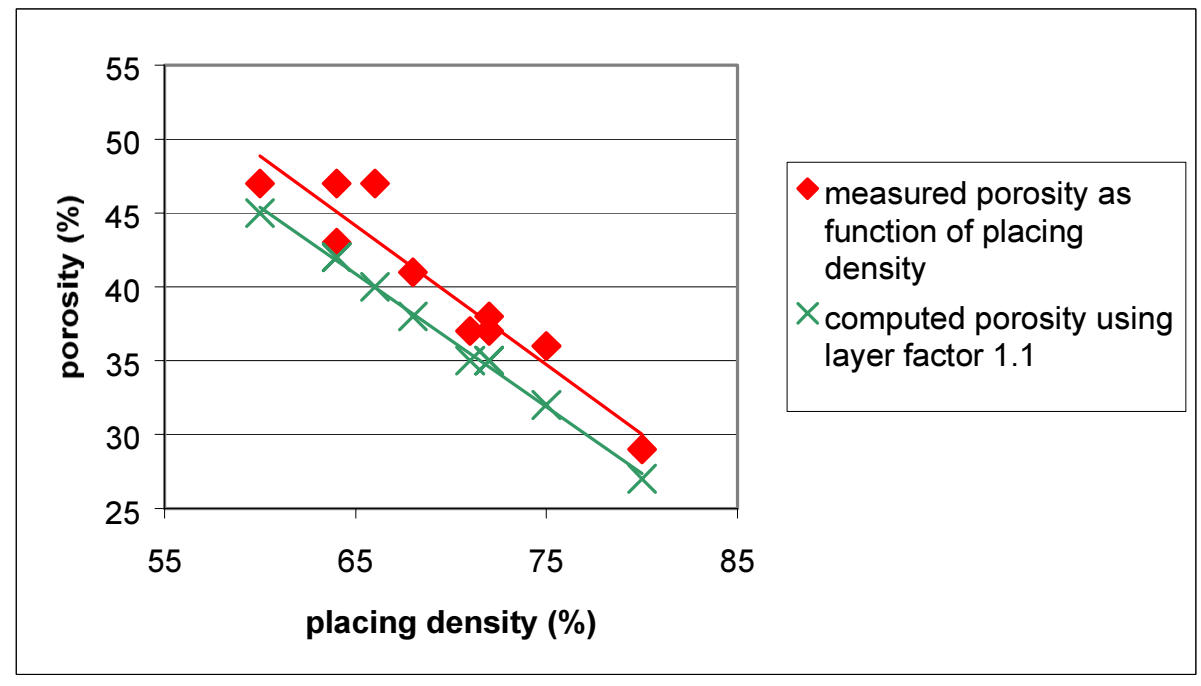

Figure 2: relation between placing density and porosity

The layers were measured using the standard hemisphere method, as described in the "Manual on the use of rock" [CUR-CIRIA, 1991]. A hemisphere with a diameter equal to half the block size was used. Apart from the hemisphere, also a rod was used to compare the results. When using a hemisphere a correction is always needed, because of the slope. More details about the effect of the use of a hemisphere or a measuring rod and the porosity were presented by BOSMA ET AL. [2002]. 


\section{PRACTICAL PLACING METHODS}

The trigger to start this research was that, although it is rather easy to create a placing density of more than $70 \%$ with cubes in a laboratory, it is quite doubtful if one can achieve this also in real life. Normally blocks can be placed:

- by crane:

- dropping blocks from a position around the water line

- placing blocks on the underwater slope itself

- by side-stone dumping vessel.

The technique of placing blocks individually on the underwater slope is not investigated. Experience from the past has shown that this is very well possible. However, it is a rather time consuming and expensive method. Therefore, contractors prefer to dump the blocks from the waterline, either from a crane, but even preferably from a side-stone dumping vessel.

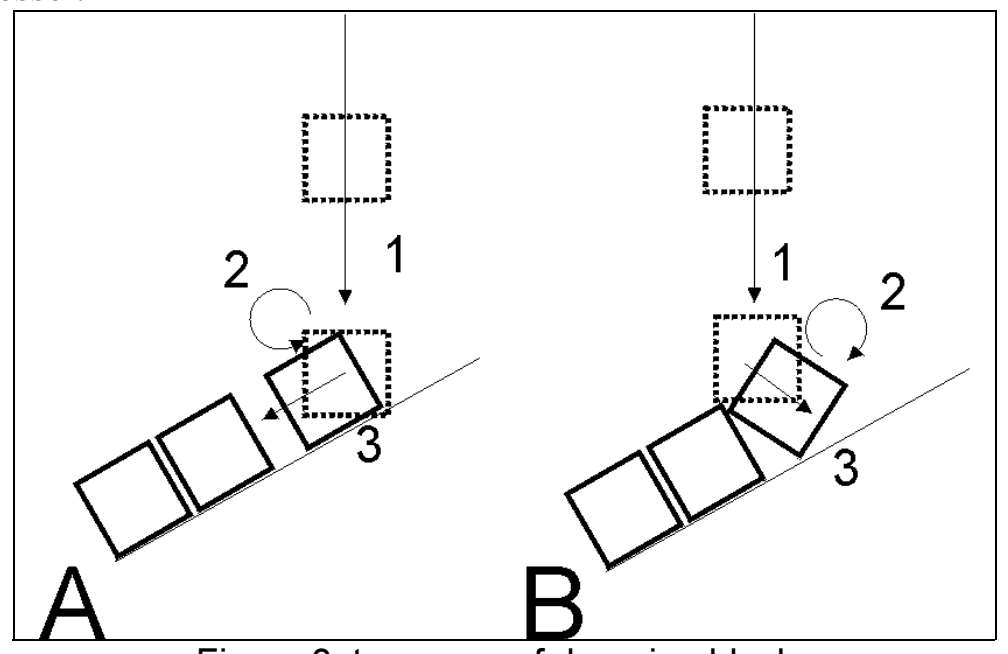

Figure 3: two ways of dropping blocks

This second method will not be discussed here, but reference is made to BISSCHOP [2002]. This paper deals with placing the blocks by dumping them from a crane. The block starts to fall from a position near the waterline. Often the block is loosened just above water, but in some cases the block is placed half in the water and then loosened. The practical problem is that the block does not fall exactly vertical, but that the "arrival position" has a Gaussian distribution. This has been investigated in detail for smaller stones.

In order to achieve a high placing density, one should drop the block very near to a previously dropped block. The idea is that the block comes on the slope (A1, see figure 3), that it turns on the slope (A2) and may slide towards the previously placed block (A3). However, when the block drops too near to the previous one (fig. B1), it first hits the previous block, turns the other way around (B2) and comes diagonally on the slope (B3). The result is that the packing becomes less. The nearer the blocks are dropped, the higher the probability that process B will occur instead of A. So, although theoretically a decrease of drop distance will lead to a higher placing density, at a certain moment the placing density will become less. This is illustrated in figure 4 . 


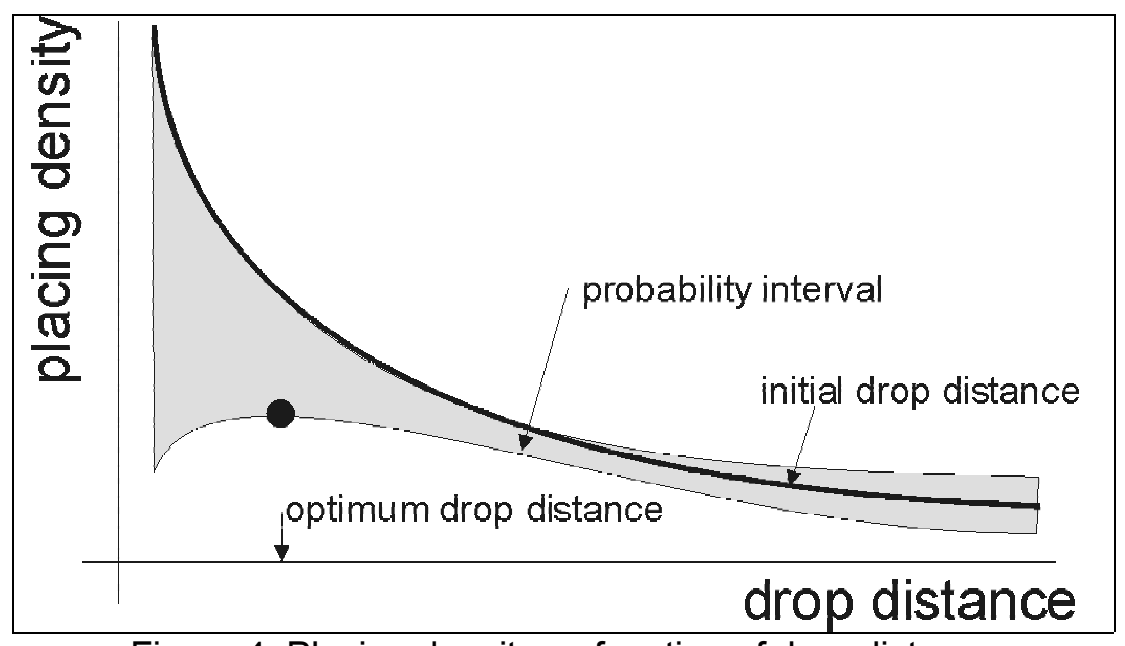

Figure 4: Placing density as function of drop distance

\section{THE TEST FACILITY AND THE TEST PROGRAMME}

The tests have been executed with cubes of $15 \mathrm{~cm}$. Smaller blocks may suffer from scale effects, larger cubes are difficult to handle. A drop height of 10 times $\mathrm{D}_{\text {cube }}$ was foreseen; so the maximum depth in the basin should be $1.5 \mathrm{~m}$. Also the difference between the drop point and the waterline needed to be investigated; this required some space. The slope was set to $3: 2$. From all these requirements followed that a basin of $2.5 \times 2.5 \times 2 \mathrm{~m}^{3}$ was needed. The blocks were dropped in water on a filter layer of loose riprap with a size of $\mathrm{D}_{\mathrm{N}}$ of 50 to $60 \mathrm{~mm}$. A toe with a height of $20 \mathrm{~cm}$ was made. Figure 5 shows the experimental setup.

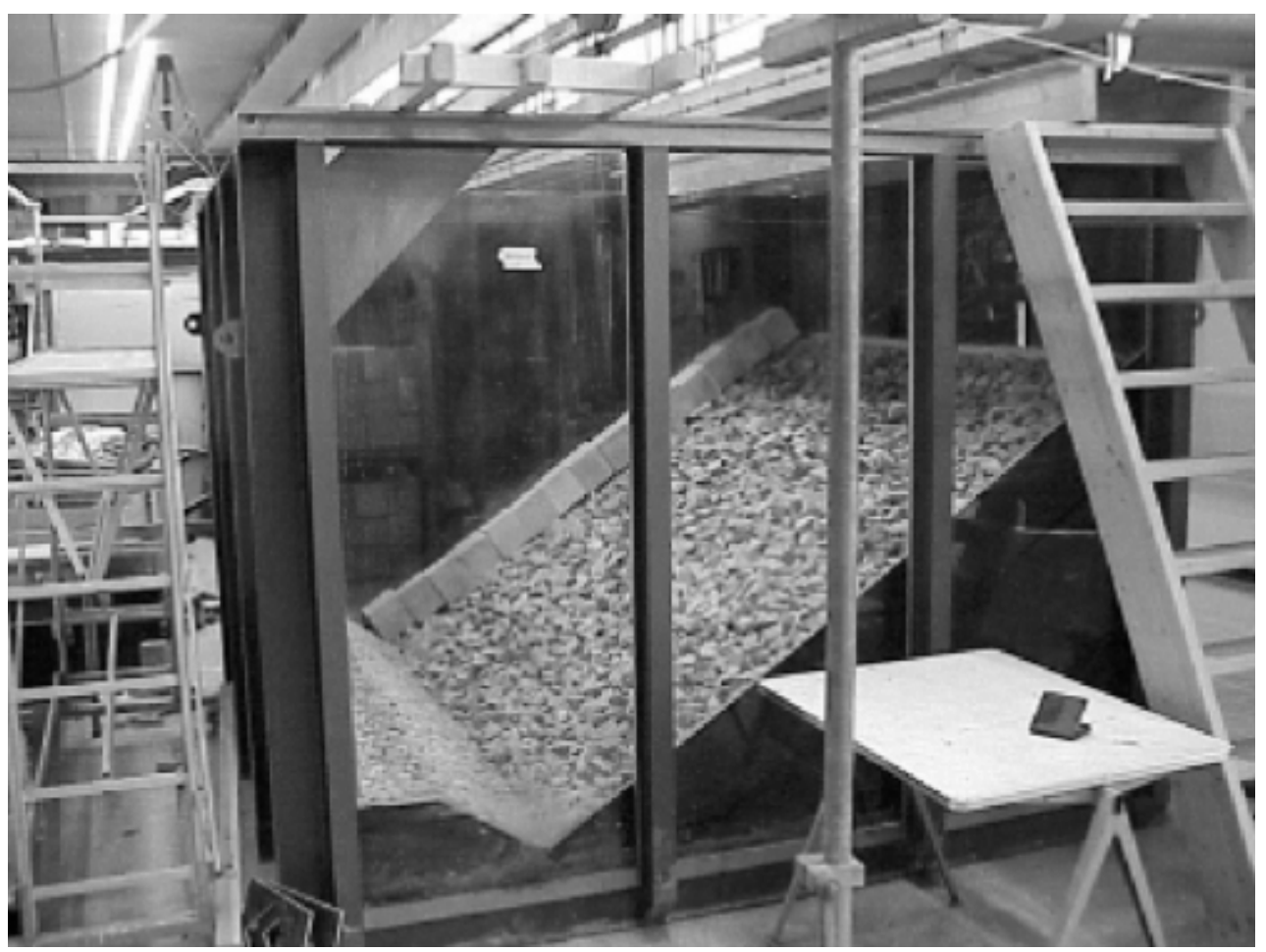

Figure 5: The test facility

During the initial tests it was also clear that when the block were dropped from above 
the waterline, quite some air was enclosed. Blocks with much enclosed air did deviate less from the vertical path than blocks without air. So this gave the impression that dropping from above water would possibly result in more accurate dropping than in case the blocks were just dipped into the water. See figure 6 . In addition, the rotation of the blocks was investigated in these initial tests. The conclusion was that all blocks did tilt somewhat, but that they did not really started to rotate.

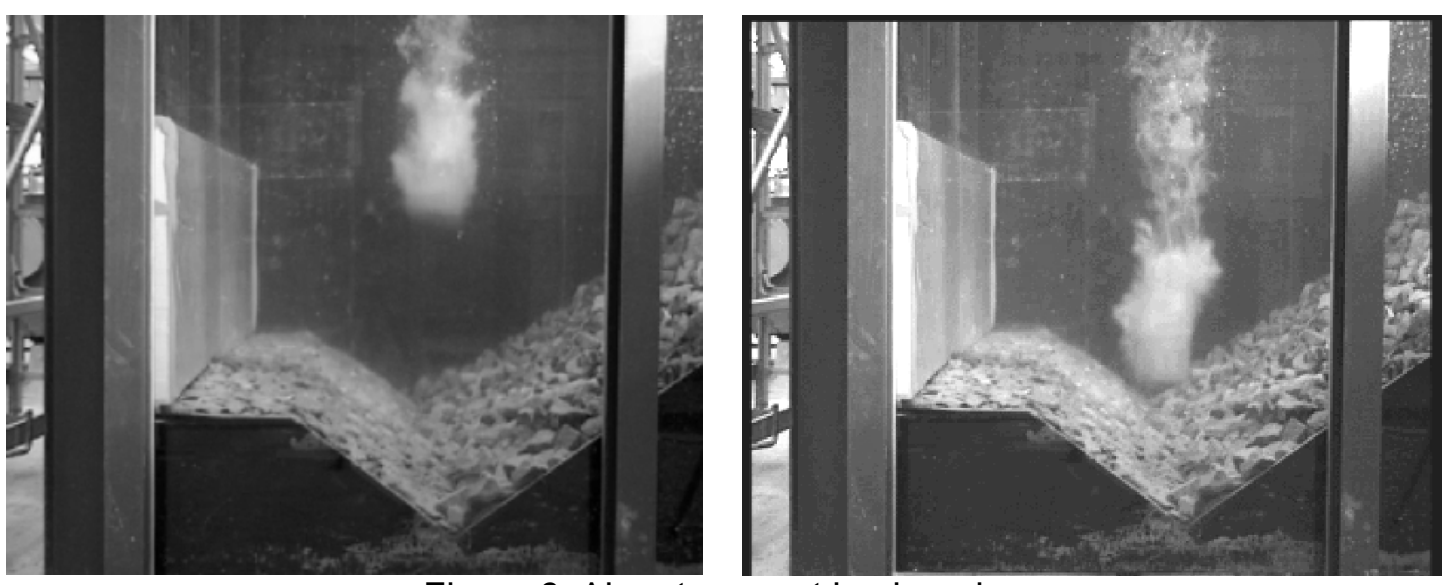

Figure 6: Air entrapment by dropping

Blocks can be dropped in several ways, resulting in different patters. One may drop the blocks in such a way that the orientation of the block is parallel to the axis of the breakwater (option 1 and 3, see figure 7). In that case one may distinguish between placing all blocks just above each other, or leave shift the blocks $50 \%$ per row.

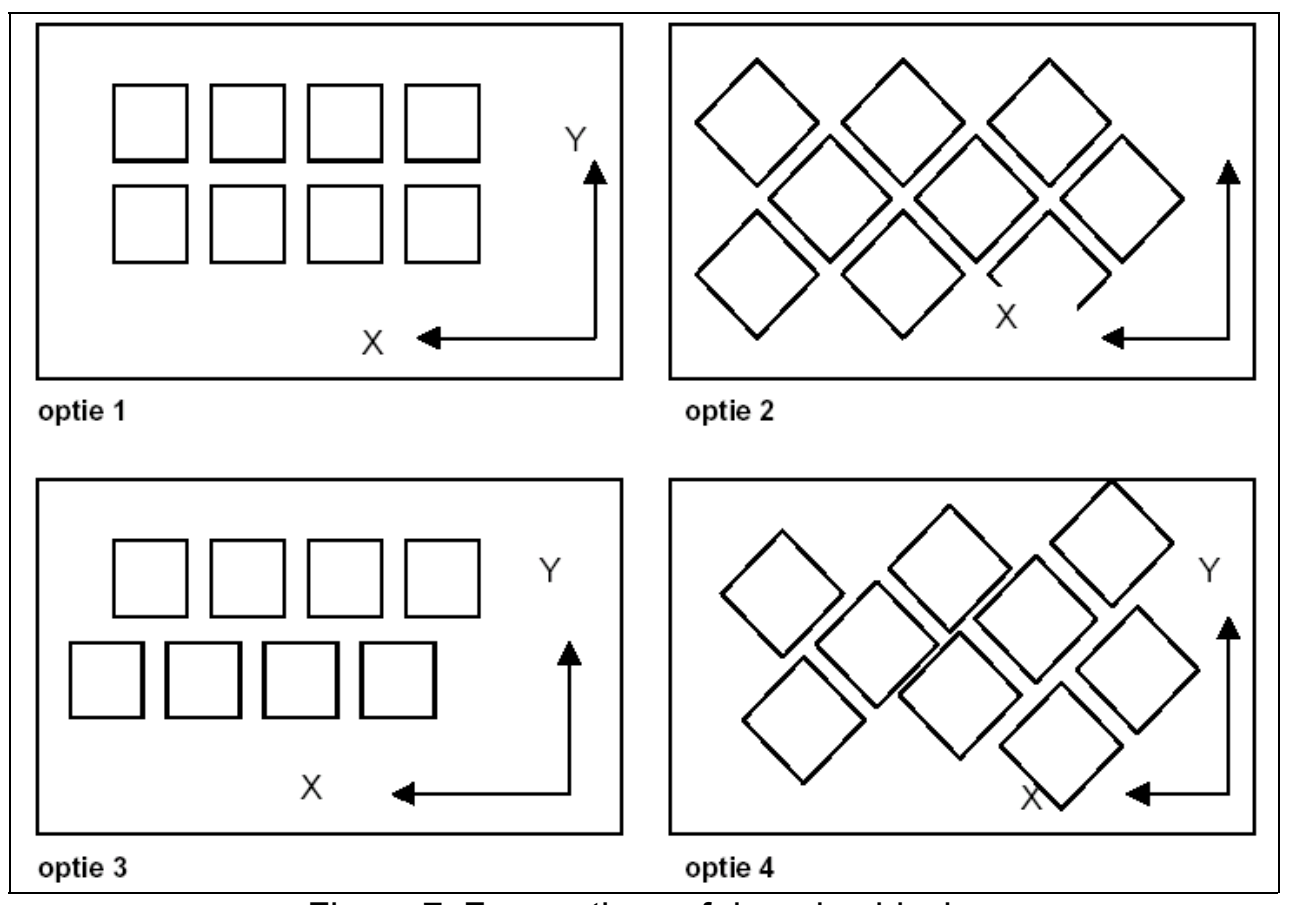

Figure 7: Four options of dropping blocks

The alternative is to place the blocks diagonally on the slope (option 2 and 4). Here one 
may try to place each block just in between the two previous ones, or one may try to place them in such a way that there are no diagonal joints. (option 4). In fact option 2 and 3 are tried, and the results showed that trials with option 1 and 4 were not very useful. Also one may vary with the placing sequence. Especially in case of diagonal dropping, one can build up the rows diagonally, but it was found that the placing sequence had not too much influence on the final result.

The main parameters to be varied where:

- variation in orientation (parallel or under and angle of $45^{\circ}$

- variation of the drop distance between the blocks

- variation of the drop distance above the water line

- variation of the waterdepth

We also assumed that variation of the slope of the breakwater might have influence. However, because most breakwaters are steep (3:2), the effect of this parameter was considered less relevant.

\section{DROP ORIENTATION}

In order to investigate the effect of the drop-orientation, tests were done by dropping blocks under a $45^{\circ}$ angle, and parallel to the slope. In all cases the placing density of blocks dropped parallel was below the required $70 \%$ (the highest density reached was $64 \%$ ). Large voids occurred between the individual blocks. The main reason of the low placing density was that with $45^{\circ}$ the blocks tend to slide into the correct position; while that is not possible with a parallel dropping. The conclusion is that parallel dropping should be avoided.

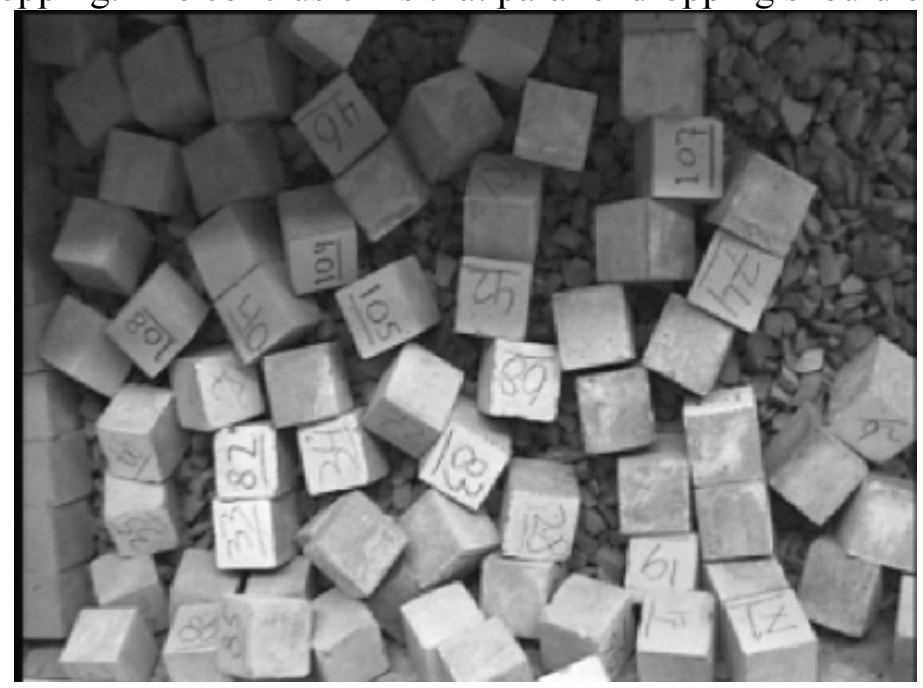

Figure 8: result of dropping blocks parallel to breakwater crest

\section{VARIATION IN DROP DISTANCE}

Because of the bad results of parallel dropping, all other tests focussed on dropping under a $45^{\circ}$ angle. A number of tests were carried out using different drop distances, both differentiating in the horizontal and in the vertical direction. The distances in the table are all given including $\sqrt{2}$, see table 1 and figure 9 . The number before the root gives a direct value of the gap, given the fact that the blocks are $15 \mathrm{~cm}$. It is clear that the placing density is quite sensitive to small variations in the drop distance. 
Table 1: variation in drop distance for diagonally dropped blocks

\begin{tabular}{llll}
\hline test $\mathrm{nr}$ & $\mathrm{x}$ & $\mathrm{y}$ & placing density \\
\hline $\mathrm{c} 1$ & $19 \sqrt{ } 2$ & $0.5^{\star} 19 \sqrt{ } 2$ & $61 \%$ \\
$\mathrm{c} 2$ & $17.5 \sqrt{ } 2$ & $0.5^{*} 17.5 \sqrt{ } 2$ & $66 \%$ \\
$\mathrm{c} 3$ & $18.25 \sqrt{ } 2$ & $0.5^{*} 18.25 \sqrt{ } 2$ & $72 \%$ \\
$\mathrm{c} 4.1$ & $18.25 \sqrt{ } 2$ & $0.5^{*} 17.5 \sqrt{ } 2$ & $71 \%$ \\
$\mathrm{c} 4.2$ & $18.25 \sqrt{ } 2$ & $0.5^{*} 17.5 \sqrt{ } 2$ & $75 \%$ \\
$\mathrm{c} 4.3$ & $18.25 \sqrt{ } 2$ & $0.5^{*} 17.5 \sqrt{ } 2$ & $72 \%$ \\
\hline
\end{tabular}

Before starting the build-up of the armour layer, a toe had been placed. It was quite essential that this toe was executed in a careful way. A low quality toe usually resulted in very low placing density values.

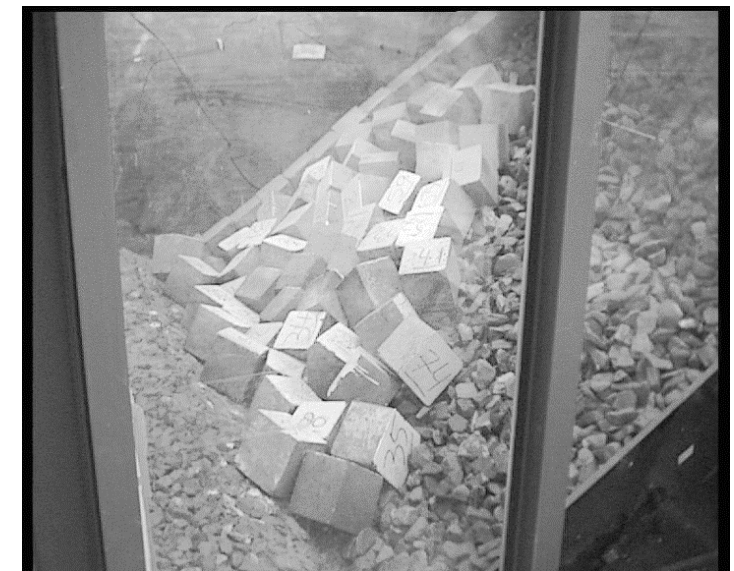

Figure 9: result of a drop test (c4.2)

In order to see the effect of variation in drop distance in vertical direction, this has also varied somewhat. This seems to be less sensitive. This is explained by the fact that the blocks because of gravity tend to slide into the correct position.

In figure 10 it is shown that small variations in drop distance in parallel (horizontal) direction have a significant influence. It is obvious that larger drop distances give a lower placing density. Smaller drop distances give indeed the behaviour as anticipated. Blocks hit other blocks, turn in the wrong way, and cause an irregular pattern with large voids. The conclusion is that in horizontal direction the distance should be 1.22 times the block size, and in vertical direction 1.16 times. It was also found that some changes in the vertical direction (especially higher values) do not directly lead to very different placing densities.

However, as can be seen from the example, the tolerances are quite small. For practical application, it means that the position of the drop point of the block has to be guaranteed by the contractor within small tolerances. In addition, it is important that at the moment of dropping, the block is not moving. In all tests the blocks were hanging completely still in the air. In reality this may be a problem. In practice this problem is often solved by the crane operator to dip the block a few centimetres into the water. 


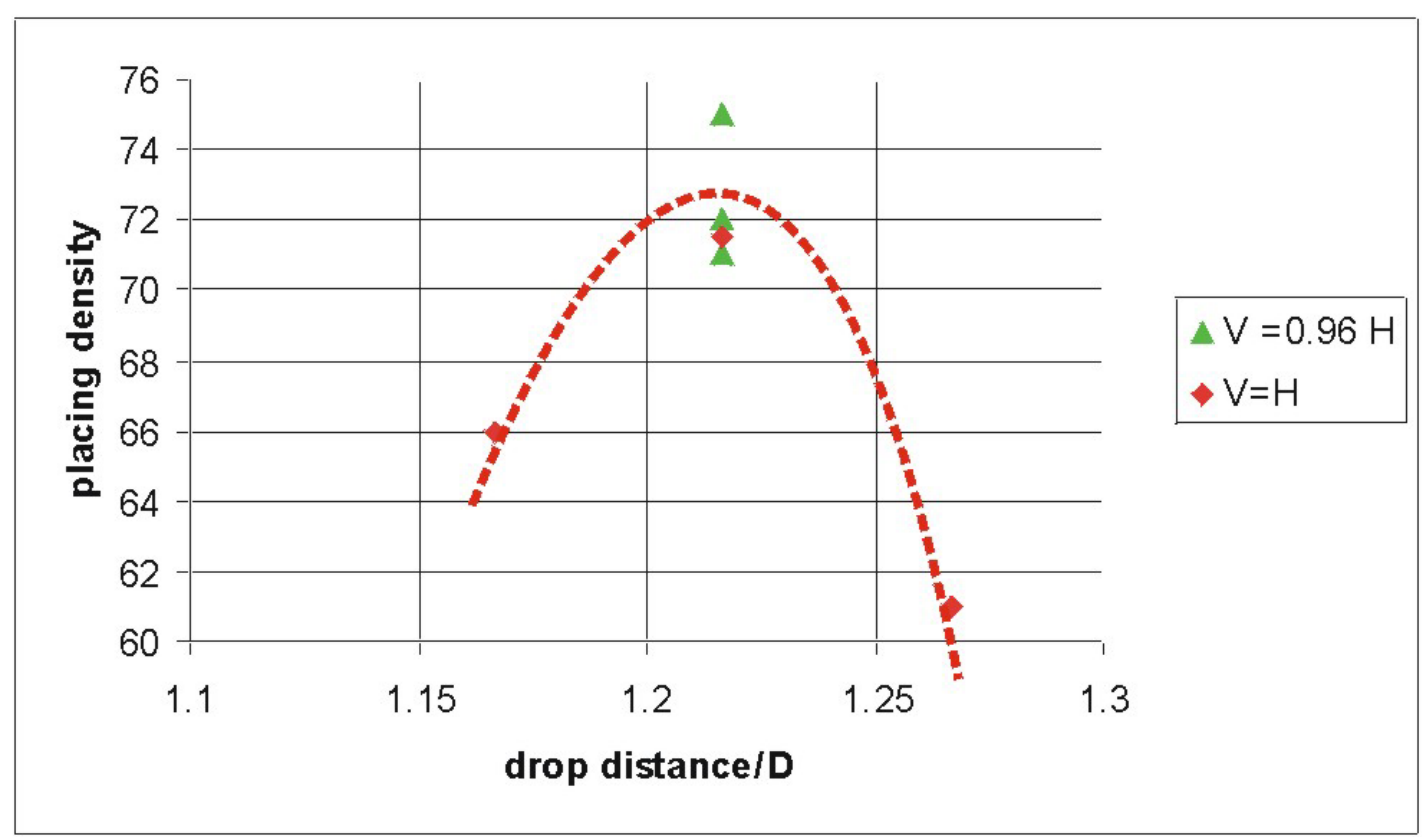

Figure 10: found relation between drop distance and placing density

\section{DROP HEIGHT ABOVE WATER}

Also was investigated the effect of the drop height above water. Blocks were dropped from a height of 2.5 times the block size and from the waterline itself. It was found that block dropped from above water did fall more precisely than blocks which were dipped into the water. See figure 11. A good explanation for this phenomenon has not been found; we assume that it has something to do with the amount of air which is surrounding the block when it is dropped from above water (see also figure 6).

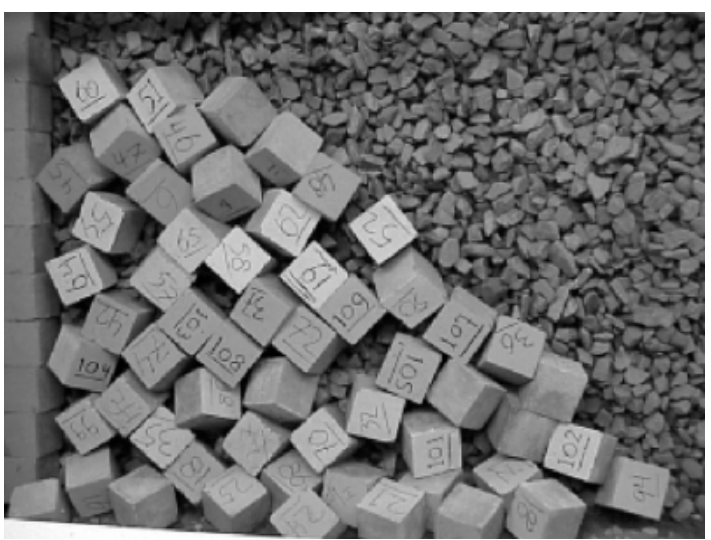

drop height $2.5 D_{\text {cube }}$, placing density $72 \%$

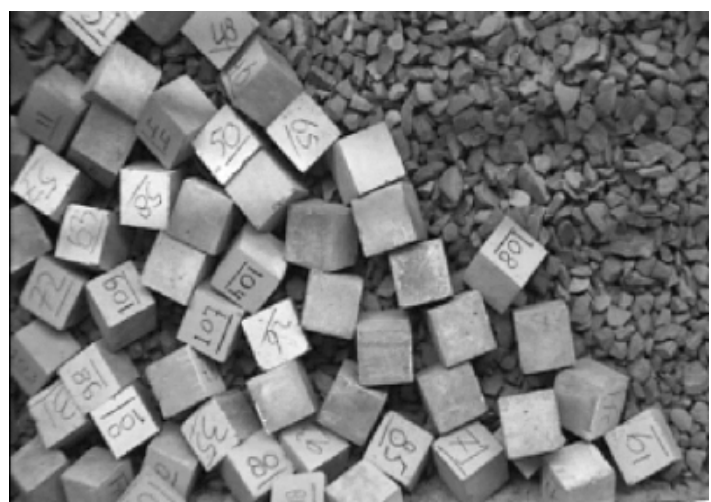

drop height 0 , placing density $64 \%$

Figure 11: Effect of drop height above water

Although it is vital that a block is hanging still before it is dropped, we had to conclude that dipping the blocks into the sea is not a good solution for this, because the placing density decreases considerably if blocks are dipped. Practical experience with the construction of the Europort breakwater has shown that drop height should not be too much, because then the cubes will break when hitting the water surface. 


\section{EFFECT OF WATERDEPTH}

Of course the water depth has a big influence. In order to quantify this effect we also did some test with approximately half of the "standard" water depth of $10 \mathrm{D}_{\text {cube. }}$ As expected, the results were much better. In two comparable tests the placing density increased from $66 \%$ to $80 \%$ when the water depth was reduced. So we can conclude that in relatively shallow water (order 6 times $D_{\text {cube }}$ ) achieving a placing density in the order of $80 \%$ is not a problem at all. Essential is in all cases, also in shallow water, that the starting line of the blocks is good. This means that the first row of blocks has to be placed very accurately. When starting on deep water on may observe with diagonal placing that after a number of rows the situation will improve, but in shallow water the number of rows is too small to allow a rearrangement.

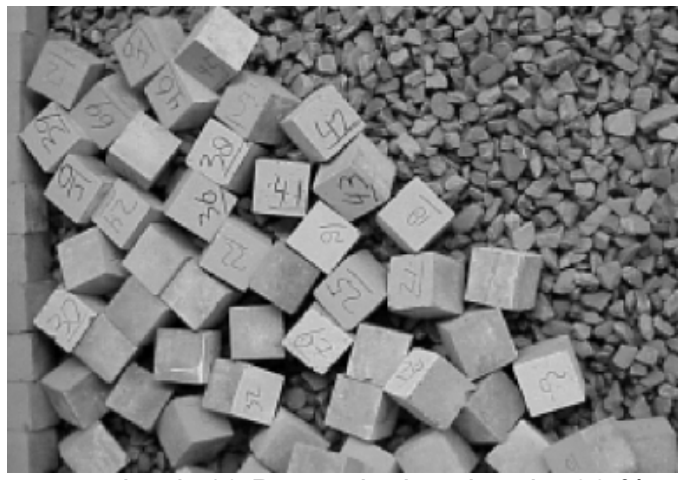

water depth $10 \mathrm{D}_{\text {cube, }}$, placing density $66 \%$

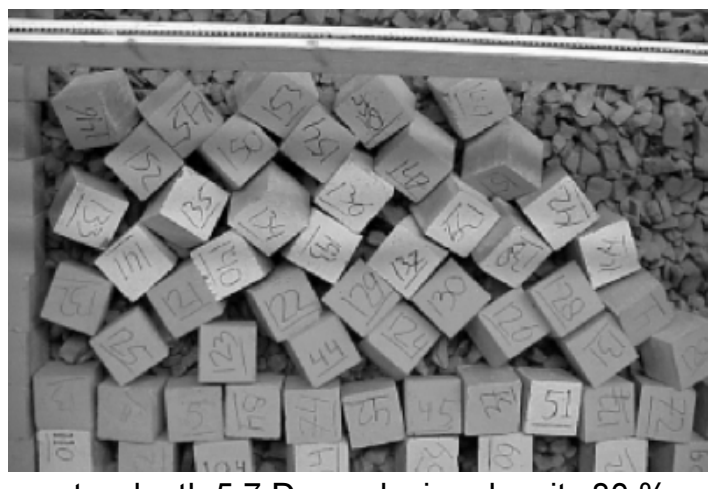

water depth $5.7 \mathrm{D}_{\text {cube, }}$ placing density $80 \%$

Figure 12. Effect of water depth on placing density

\section{CONCLUSIONS}

So the general conclusions are that, by using a crane, a block density of more than $70 \%$ can be achieved, provided that:

- cubes are placed under an angle of $45^{\circ}$

- the water depth should not be more than 10 times $\mathrm{D}_{\text {cube }}$

- the distance between the drop points is carefully determined

- block are dropped above the waterline from a standstill position

In addition, it has been that the quality of the block placement depends very much on the quality of the toe on which the blocks are placed.

\section{ACKNOWLEDGEMENTS}

The test were executed in the laboratory of fluid mechanics of the Delft University of Technology, and where funded from the general research budget of the Section of Hydraulic Engineering. This paper is mainly based on research executed in the laboratory for Fluid Mechanics at the Delft University of Technology. The tests themselves were carried out by Kees van der Vliet in the framework of his M.Sc.-study [VANDERVLIET, 2002].

\section{REFERENCES}

Bisschop, C. [2002] Model investigation to the placements of cubes on a breakwater using a side-stone dumper. M.Sc. Thesis Delft University of Technology, (in Dutch) 
(http://www.waterbouw.tudelft.nl/education/reports/2002/2002Bisschop.htm)

Bosma, C., Verhagen, H.J., d'Angremond, K. and Sintnicolaas, W. [2002] Void porosity in coastal structures. Proceedings of the $28^{\text {th }}$ International Conference on Coastal Engineering

CUR-CIRIA [1991] Manual on the use of rock in coastal and shoreline engineering, CUR report 154, Gouda, The Netherlands

VanDenBosch, A, d'Angremond, K, Verhagen, H.J., Olthof, J. [2002] Influence of the density of placement on the stability of armour layers on breakwaters. Proceedings of the $28^{\text {th }}$ International Conference on Coastal Engineering

VanDerVliet, C. [2001] Practically achievable placing density of cubes in the armour layer of a breakwater. M.Sc. Thesis, Delft University of Technology, (in Dutch) (http://www.waterbouw.tudelft.nl/education/reports/2001/2001VanderVliet.htm)

VanGent, M.R.A. and Spaan, G.B.H. [1998] Breakwaters with a single layer of cubes, model investigation for the Maasvlakte expansion. Delft Hydraulics report H3387, Delft Hydraulics (in Dutch) 
KEYWORDS - ICCE 2002

POSITIONING OF CUBES ON A BREAKWATER SLOPE

Henk Jan Verhagen, Kees d'Angremond, and Kees van der Vliet

Breakwaters

Coastal structures

Cubes

Blocks

Construction

Placing density

Porosity 